pÿlmmigrants use of healthcare in their country of origin : the role of social integration, discrimination and the parallel use of health care systems

Kemppainen, Laura

2018-06

Kemppainen , L , Kemppainen , T , Skogberg , N , Kuusio , H \& Koponen , P 2018 , ' pÿlmmigrants use of healthcare in their country of origin : the role of social integration, discrimination and the parallel use of health care systems ' , Scandinavian Journal of Caring Sciences , vol. 32 , no. 2 , pp. 698-706 . https://doi.org/10.1111/scs.12499

http://hdl.handle.net/10138/302387

https://doi.org/10.1111/scs.12499

unspecified

acceptedVersion

Downloaded from Helda, University of Helsinki institutional repository.

This is an electronic reprint of the original article.

This reprint may differ from the original in pagination and typographic detail.

Please cite the original version. 


\title{
Immigrants' use of healthcare in their country of origin: The role of social integration, discrimination and the parallel use of healthcare systems
}

\author{
Manuscript, accepted for publication in Scandinavian Journal of Caring Sciences \\ (manuscript published 29.5.2017) \\ Laura Kemppainen (neé Lyytikäinen) \\ Department of Social Research, University of Turku, Finland
}

Teemu Kemppainen

Department of Social Research, University of Helsinki, Finland

Department of Social Research, University of Turku, Finland

Natalia Skogberg, Hannamaria Kuusio \& Päivikki Koponen

National Institute for Health and Welfare

\begin{abstract}
Aims

The objective of this study was to elucidate the utilisation of Russian healthcare by immigrants of Russian origin living in Finland (cross-border healthcare). The study examined the association of cross-border healthcare with social integration and discrimination. Moreover, it studied whether cross-border healthcare was used as an alternative to the host-country's healthcare system.

Methods

Data from the Finnish Migrant Health and Wellbeing Survey (Maamu) was utilised. The number of respondents of Russian origin was 545 . The main analytical method was logistic regression. The outcome variable was based on a survey item on seeking physician's treatment or help abroad during the last 12 months. Social integration was measured multi-dimensionally, and the indicator was extracted by multiple correspondence analysis. Ethical approval for the study was obtained from the Ethical Committee of the Uusimaa Hospital Region.
\end{abstract}

\section{Results}

We found that $15.4 \%$ of the respondents had visited a physician in Russia during the last 12 months. $10.4 \%$ had experienced discrimination in Finnish health services during their stay in Finland. Stronger social integration predicted less frequent utilisation of cross-border healthcare. Experiences of discrimination or unfairness were associated with higher odds for seeking cross-border healthcare. Cross-border healthcare was typically used in parallel to the Finnish services.

\section{Conclusions}

Our findings on integration and discrimination emphasise the importance of general integration policy as well as cultural competence in healthcare. Parallel use of healthcare systems entails both risks (e.g double medication, problems of follow-up) and opportunities (e.g. sense of agency), which should be further investigated.

Keywords: cross-border healthcare, transnational healthcare, cultural competence, immigrant patients, ethnic minority, social integration, service selection, discrimination, Russia, Finland 


\section{Introduction}

Recent studies have shown that immigrants may face discrimination, culturally incompetent care and other barriers to high-quality healthcare in their host-countries (1-4). One solution to obtain more satisfactory healthcare is to seek help from one's country of origin. The ease of international travel and the widening of available information through the Internet have created a growing global market for healthcare and patient mobility (5-6). The patient flows are most visible in the border regions, when people are returning 'home' for healthcare or looking for cheaper healthcare in the neighbouring country (5). The Finnish-Russian border is among the longest external borders of the EU and the Schengen area. The geographical proximity and the ease of travel create an interesting framework for studying immigrants' use of cross-border healthcare (CBHC), i.e. visiting a physician in the neighbouring country. In this article, we study the utilisation of Russian healthcare by immigrants of Russian origin living in Finland. Our aim is to study whether social integration, experiences of discrimination and the use of host-country health services are associated with the utilisation of $\mathrm{CBHC}$.

Most of the literature on the field of cross-border healthcare (CBHC) studies comes from United StatesMexico border studies (e.g. 7-12) and from studies of cross-border healthcare inside the European Union (e.g. 13-15). Research reviews have pointed to a need for further research on transnational healthcare utilisation of immigrants in Europe (16-18). Recent studies have found that immigrants in Europe travel to their countries of origin in search of healthcare. Studies have documented medical travels of Turkish immigrants in Denmark (18-20), Romanians and other immigrant groups living in Ireland (21-22) and Polish immigrant women in Spain, the UK and Germany (23). To our knowledge, healthcare utilisation of immigrants of Russian origin has not been addressed in prior studies, and studies on cross-border healthcare of immigrants in Finland are few (however, see 24-25).

According to previous studies, the main reasons for immigrants to seek healthcare abroad are affordability, culturally based lack of knowledge and linguistic skills as well as negative attitudes towards the host- 
country's healthcare system $(18,19,21,22,23,26)$. Also, immigrants' health status, such as a pre-existing chronic condition or a new illness or accident occurring during the stay abroad, is associated with CBHC utilisation (19). Alongside socio-demographic and health issues, social and cultural factors are seen as important in the patients' choice of $\operatorname{CBHC}(19,23,26)$. Şekercan et al. (19) argue that medical cultures of the immigrants' country of origin shape patients' perceptions on how healthcare should be provided and how healthcare providers are expected to act. Lee et al. (26) found in their study of Korean immigrants in New Zealand that immigrants do not travel for medical care only to look for effective, but also affective, care in an emotionally comfortable and familiar place. Also, Main (23) notes the cultural competence of the doctors and the patients' personal comfort as important reasons for Polish immigrants in London and Barcelona to travel to Poland for care.

Social integration is a central theme in migration studies (e.g. 27-28). We understand social integration as a dynamic process in which an individual becomes a part of a social system. More precisely, integration entails participation in the social, economic, cultural, political and legal fabric of the host society (29-30). There is a scarcity of evidence on the association of social integration with $\mathrm{CBHC}$ in the European context (in the U.S. context, see 11). In this article, we examine integration from the perspectives of institutional and social ties, linguistic skills and self-identification. Furthermore, research has shown that immigrants often face discrimination and culturally incompetent care in healthcare services (for reviews, see 1-4), but the association of experiences of discrimination with the utilisation of $\mathrm{CBHC}$ has not been addressed. Our study examines the cultural and social factors related to the utilisation of $\mathrm{CBHC}$ by analysing its association with social integration and experiences of discrimination. We also examine whether $\mathrm{CBHC}$ is used as an alternative to the host-country's healthcare system or as parallel.

Our research questions are:

1) To what extent does the utilisation of cross-border healthcare depend on social integration?

2) What is the role of experienced discrimination regarding the utilisation of $\mathrm{CBHC}$ ? 
3) Is the use of host-country health services associated with the utilisation of CBHC?

In what follows, we describe the theoretical background of our study. After presenting data and methods, we introduce and discuss our empirical findings, which show that social integration and experiences of discrimination are independently associated with the use of $\mathrm{CBHC}$, and that the Finnish and Russian healthcare systems are typically used as parallels instead of alternatives.

\section{Background}

\subsection{Social integration, discrimination and the parallel use of healthcare systems}

The role of social integration, discrimination and the parallel use of healthcare systems in the utilisation of cross-border healthcare can be conceptualised using the model of health service selection (31). Leduc and Proulx (31) describe the process of service selection starting from 1) the recognition of the need for health services, which is followed by 2) the information search from different sources, 3) the evaluation of available alternatives, 4) the decision to select a specific health service, and, finally, 5) the retrospective evaluation of the decision.

Österle et al. (6) and Glinos et al. (5) have examined health service selection from transnational perspectives. The work of Österle et al. (6) can be used to extend the third phase of the service selection model, i.e. the evaluation of available alternatives, which is central in studying why immigrants choose to use health services abroad instead of the services of their host-country. Österle et al. (6) define the substantial dimensions determining the selection of a healthcare provider, including costs (economic and psychological), access (service availability and ease of travel), quality (provider and system quality; reputation) and socio-cultural factors (see also 5).

As mentioned above, our aim is to study whether the utilisation of $\mathrm{CBHC}$ is associated with social integration, experiences of discrimination and the use of host-country health services. Next, we will 
develop our hypothesis building on the theoretical frameworks of Leduc and Proulx (31) and Österle et al. (6), as well as prior findings in studies of $\mathrm{CBHC}$.

To what extent does the utilisation of cross-border healthcare depend on social integration?

Social and cultural perceptions of healthcare are important in the patients' choice of use of $\operatorname{CBHC}(6,19)$. Studies have shown that the length of stay in the host-country is associated with healthcare utilisation: recently arrived immigrants tend to utilise healthcare services less regularly than those who have stayed in the country for longer (30-33). During the integration process, immigrants may gain knowledge of the healthcare system and its utilisation, which can create more trust and comfort in using the local healthcare services (see 31). Integration to the host society is associated with the daily behaviour and lifestyle choices of immigrants, and thus, we assume that the level of integration also impacts health behaviour and different phases of the health service selection process. For example, an information search is facilitated by the host-country's social networks and familiarity with the local system, and the evaluation of alternatives and the decision-making depend on socio-cultural factors such as norms, beliefs and attitudes, which are influenced by local social networks (cf. 6, 34). Lack of trust and knowledge of the host-country's healthcare system can act as a push factor for seeking CBHC. Hence, we expect that the more integrated immigrants are less likely to seek healthcare from their country of origin than less integrated immigrants (H1). Our data allows us to measure integration not only by the length of stay, but also using the socio-cultural dimensions of integration, covering the type of residence permit, subjectively perceived nationality, language proficiency, social networks with the locals and following of the host-country's media.

What is the role of experienced discrimination regarding the utilisation of CBHC?

Discrimination constitutes one of the socio-cultural dimensions of health service selection. The association between $\mathrm{CBHC}$ and experiences of discrimination has not been studied yet. Prior studies have documented inequalities in the use and accessibility of healthcare, which are related to immigrant status (1-4). Immigrants may not have legal access to public healthcare, and even immigrants with guaranteed access 
face obstacles to quality care because of individual, socio-cultural, economic, political or administrative reasons (3, see also 6). Discrimination, unfair or discourteous care, stereotypical attitudes towards ethnic minority patients and culturally-based lack of communication between the doctor and the minority patient can act as barriers to quality care (for reviews, see 35,2 p. 342, 36) and push immigrants to look for culturally comfortable care abroad (cf. 6, 23, 26).

We assume that experiences of discrimination and unequal treatment in the healthcare services impact the service selection process, and especially the retrospective evaluation of the selection decision. Incidences of discrimination also affect the later evaluation of available alternatives. The discriminating provider and institution, or the whole system, are likely to be avoided in the later decisions, if financially possible. In sum, fear of discrimination can act as a barrier to healthcare utilisation (see also 37). It is likely that perceived discrimination in healthcare pushes immigrants to look for healthcare abroad (H2).

Is the use of host-country health services associated with the utilisation of CBHC?

The decision to select a specific health service (31) does not necessarily exclude other alternatives. For example, a second opinion is sometimes sought abroad (19). Recent research has found that immigrants use healthcare services abroad as supplementary, rather than alternative, to the medical services in their country of residence (18-19). We examine whether immigrants in Finland utilise the host-country and foreign systems as parallel or only one system. Theoretically, we can formulate two equally plausible hypotheses. First, the healthcare systems of the corresponding countries may provide similar healthcare services, and immigrants mainly seek help from either one or the other. Hence, the use of CBHC would crowd out the use of the host-country's system, and vice versa. This leads to hypothesis that those who have sought care from Finland are less likely to use $C B H C$ (H3.1). However, another possibility is that the use of $\mathrm{CBHC}$ follows the logic of individual propensity to seek care, whereby people with a higher tendency to use medical services use both Finnish and cross-border healthcare (H3.2). 


\subsection{Immigration and healthcare in Finland}

Immigration to Finland has grown rapidly since the 1990s. In 2016, there were around 330,000 foreign language speakers in Finland, which is about $6 \%$ of the population. The largest foreign-speaking group in Finland is the Russian speakers, who comprise almost $22 \%$ (around 72,000 persons) of all immigrants (38). The biggest group of immigrants with a Russian background are the Ingrian Finnish, who were permitted to move to Finland as Finnish returnees since 1990. The Ingrian Finnish could get a residence permit on the basis of remigration if they had adequate Finnish language skills, and if they themselves, one of their parents or at least two of their grandparents were or had previously been Finnish by nationality. There were around 30,000 Ingrian Finnish returnees before the system was dismantled in 2016 (39).

The Finnish state guarantees a universal right to healthcare services to all the residents of the country. All Finnish citizens and foreign citizens with a residence permit are covered by the National Health Insurance (NHI), which also reimburses a small part of the costs from using private health services (40). The quality of Finnish healthcare services is considered to be good by its residents. In the Eurobarometer survey, $88 \%$ of the respondents in Finland evaluated Finnish healthcare services as very good or fairly good (41). The most often mentioned challenges that the Finnish healthcare system faces are shortage of GPs, particularly in rural areas, long waiting times and increasing healthcare costs (42).

One prominent difference in the Finnish and Russian healthcare services is in the referral system. In Finnish public healthcare, a patient has to first see the general practitioner (GP) or a nurse, who can then assess whether a specialist is needed. In the private sector, the patient can freely choose a specialist, but at a higher cost. In Russia, patients are not obliged to see a primary care internist or GP before seeing a specialist, but they have the right to choose their primary care providers and individual doctors within a polyclinic (43). 


\section{Data and methods}

\subsection{Maamu-survey}

This study uses data from the Finnish Migrant Health and Wellbeing Survey (Maamu) conducted in Finland between 2010 and 2012 (44). The survey was carried out in six urban municipalities with a proportion of immigrants higher than in most Finnish municipalities: three in the metropolitan area (Helsinki, Espoo, Vantaa) and three in other parts of the country (Turku, Tampere, Vaasa). Three large immigrant groups in Finland were included in the survey: Russian, Somali and Kurdish origin immigrants. The current study is restricted to the Russian sub-sample of the survey.

A representative random sample of 1000 persons of Russian origin aged 18-64 years was drawn from the National Population Registry. Selection criteria were Russia or the former Soviet Union as country of birth, Russian or Finnish as the native language, and residence in Finland for at least one year. The sample was stratified by the municipality and the gross sample size for each stratum was determined according to the size of the immigrant population living in the municipality, ranging from 100 (Vaasa) to 305 (Helsinki).

Ethical approval for the study was obtained from the Coordinating Ethical Committee of the Helsinki and Uusimaa Hospital Region. The survey data were obtained by structured face-to-face interviews, which were carried out by trained bilingual interviewers; a written informed consent was obtained from all of the participants. The participants could choose the interview place and whether to use Russian or Finnish; most interviews were conducted in Russian. The participation rate was $55 \%$.

\subsection{Statistical methods}

Different sampling probabilities and nonresponse were handled using sampling weights that were adjusted by response probabilities based on age group, sex, ethnic group, study location and marital status. Logistic regression analysis took these adjusted sampling weights, stratification of the design and finite population 
correction into account. Interactions were used to to examine whether the regression results differ by gender.

Multiple correspondence analysis (MCA) was used as a data reduction tool in the construction of the variable on social integration. By enabling the description and extraction of latent patterns in a set of categorical variables, MCA can be considered analogous to factor and principal component analysis in the cases of continuous variables. In our study design, data reduction was necessary, since the strong covariation of the items would have been problematic in regression analysis (multicollinearity). MCA was run using Burt's method and the standard normalised coordinates were extracted (E.g.45-47).

Analyses were conducted with STATA 14.1.

\subsection{Variables}

The outcome variable was based on the question inquiring from which countries the respondent had sought physician's treatment or help abroad during the last 12 months.

The set of predictors was selected and refined as a result of an iterative process combining insights from the existing literature with empirical examination. Our indicator of social integration was based on a multiple correspondence analysis of the following categorical variables: the basis of residence permit, the length of stay in Finland, citizenship status, subjective nationality, Finnish media following, the amount of Finnish friends and the command of Finnish or Swedish (the official languages of Finland). The first dimension of the MCA solution explained $77 \%$ of the total variance in the set of items (adjusted principal inertia) (47), and we used it to indicate respondents' social integration. For the purposes of the descriptive analysis, we divided the latent dimension into two groups from the mean (low/high integration).

Indicators measuring the experiences of discrimination or unfairness in Finnish health services (yes/no) and visiting a Finnish physician during the last 12 months were constructed from the survey data. 
We included the following control variables in the model. Health status of the respondent was covered by two variables: 1) chronic illness or a health problem, feeling of sickness or injury that hinders functional or work ability; 2) the variable on self-rated health was dichotomised to indicate poor health (combining somewhat poor and poor). Sociodemographic variables included age, gender, location, education, economic activity, monthly net household income, self-perceived economic hardship and marital status (see table 1).

--- Table 1 about here ---

\section{Results}

First, we report the descriptive results (see table 1). $15.4 \%$ of the respondents had visited a physician in Russia during the last 12 months, and $10.4 \%$ had experienced discrimination in Finnish health services. As mentioned above, we approached integration using many variables. A residence permit was usually based on Ingrian background or family ties; around $60 \%$ of the respondents had stayed in Finland over 10 years, and $43 \%$ reported good command of spoken Finnish. Almost half of the respondents had Finnish citizenship. In terms of subjective nationality, over $61 \%$ considered themselves Russians, while only around $13 \%$ identified as Finnish. Two-thirds followed Finnish media daily, but over $60 \%$ had no Finnish friends.

Next, the MCA indicator of social integration is described in relation to its constitutive items. The value of the indicator is positively related to the length of stay in Finland: the score for those who have lived less than five years in Finland is, on average, -1.18 , while for those having stayed 15 years or more, it is 0.89 . The indicator also behaves logically with the other integration items: the following of Finnish media (those who followed monthly or less frequently score -0.50 /those following daily: 0.16 ), amount of Finnish friends (none: -0.40/five or more: 1.01), command of Finnish official languages (poor: -1.23/good: 0.73 ) and citizenship (no: -0.69/yes: 0.81). Those with Ingrian Finnish background residence permit were typically strongly integrated (0.52), while residence permit granted on the basis of work was associated with weaker 
integration (-1.14). In terms of subjective nationality, those who considered themselves Finnish scored high (1.08), whereas the ones considering themselves Russians were more weakly integrated (-0.42).

\section{--- Table 2 about here ---}

The first column of table 2 reports the bivariate regression results. Our research questions one and two were concerned with the association of integration and experiences of discrimination with the utilisation of CBHC. We found that those who were more integrated into Finnish society were considerably less likely to seek $\mathrm{CBCH}$ compared to less integrated respondents: a one-unit increase in the integration indicator implies a fifty percent decrease in the odds of seeking CBHC (OR 0.53). Those who had experienced discrimination in Finnish health services were clearly more likely to use $\mathrm{CBHC}$ compared to those with no experience of discrimination (OR 2.24). Furthermore, those who had visited a Finnish physician during the last year were noticeably more likely to seek CBHC (OR 2.55).

Regarding research questions one and two, integration and experiences of discrimination were independently associated with the utilisation of $\mathrm{CBHC}$ in the final adjusted model as well. In line with hypothesis one, social integration was positively associated with seeking CBHC: a one-unit increase in the integration score decreased the odds for seeking CBHC by 59\% (OR 0.41). In agreement with hypothesis two, those who had experienced discrimination in Finnish healthcare services had higher odds (OR 2.44) of utilising $\mathrm{CBHC}$ compared to those with no experience of discrimination.

In terms of research question three regarding the parallel use of the Finnish system and CBHC, our analysis showed that those who had used Finnish health services had higher odds (OR 3.09) of CBHC use than those who had not used the Finnish system, which supports the hypothesis 3.2 .

Concerning the control variables, utilisation of $\mathrm{CBHC}$ was significantly associated with having health problems; chronic health problems and poor self-rated health implied higher odds for seeking CBHC in the bivariate and adjusted models. The coefficients were somewhat attenuated in the final model. In the final model, respondents with perceived economic hardship had lower odds (OR 0.34) for seeking CBHC; the 
coefficient of the objective income variable was weaker and significant only at the level of 0.1 , but it points towards the possibility that those with higher income would be less likely (OR 0.44 ) to utilise CBHC. Finally, tertiary education was a strongly significant and positive predictor of $\mathrm{CBHC}$ utilisation in the bivariate model, and it was significant at 0.01 also in the full model (OR 1.99).

As mentioned in the methods section, we tested the interaction of gender with other predictors. Table two presents the results of the interaction variable with adjusted main effects. We found that only the impact of marital status was modified by gender. Compared to men who were not married and lived alone (reference category), men and women who were married or lived with a partner were more likely to seek CBHC (men: OR 3.87; women: 4.82); single women living alone had the highest odds ratio (8.44) for utilisation of CBHC. The coefficient of married or cohabiting men was obtained from the row 'married or cohabitation'. That of cohabiting women was obtained by multiplying the odds ratios from the rows 'woman', 'married or cohabitation', and 'interaction: woman \& married/cohabitation'. The row 'woman' indicates the odds for single women.

\section{Discussion}

In this article, we studied the use of cross-border healthcare by immigrants of Russian background in Finland. We hypothesised that social integration is negatively associated with seeking $\mathrm{CBHC}$, while experiences of discrimination act as a push factor for using $\mathrm{CBHC}$. Both of these hypotheses were supported by our empirical findings. Our final interest was in the parallel use of foreign and Finnish healthcare systems. In line with previous research (18-19), we found that the healthcare systems are often used in parallel, rather than as alternatives.

The implications of $\mathrm{CBHC}$ and its relationship with integration and discrimination are multi-faceted. On one hand, $\mathrm{CBHC}$ opens up new service opportunities for immigrants and can align with their treatment preferences. Moreover, medical travel and navigating different healthcare systems may contribute to the patient's sense of agency $(18,23,26)$. However, cross-border use of healthcare may also imply lower 
integration, and the use foreign healthcare can further disconnect the immigrant from the host-country services. Furthermore, while transnational connections can create feelings of comfort and belonging, which are important for general health and wellbeing, some immigrants may see cross-border healthcare as their only option due to, for example, insufficient knowledge of the host-country's healthcare system or fear of discrimination. In these cases, the healthcare system of the host-country should take people from diverse backgrounds into account to provide equal access and culturally competent care (48-49).

In total, $15.4 \%$ of the surveyed immigrants had used cross-border healthcare. Despite the close proximity of their country of origin, the use of $\mathrm{CBHC}$ was lower among the Russian immigrants in Finland than, for example, Turkish immigrants in Denmark (26.6\%) and in the Netherlands (21.3\%) (18-19). This may imply a shorter cultural distance between Finnish and Russian medical systems, which can decrease the likelihood of medical travel (6) or differences in the inclusiveness of healthcare. Immigrants of Russian origin, and especially Finnish Ingrian origin, may be more integrated into Finnish society and face less ethnic discrimination than the population of Turkish origin in Denmark and the Netherlands. However, our results show that over $10 \%$ of the immigrants of Russian origin in Finland had faced discrimination in health services. Perceived discrimination was also independently associated with the use of CBHC. Experiences of discrimination may also interfere with the integration process because they create distrust and discomfort towards the host-country services.

There is also a socio-economic aspect to $\mathrm{CBHC}$ and integration. Earlier research has found that more affluent immigrants often seek help in private health clinics and hospitals in their country of origin, which they perceive as offering better services than the public health system in their country of residence, but still remains a cheaper option than the host-country's private services $(22,26)$. Our results suggest a more complex picture of the association between economic resources and CBHC. Among our respondents, people with higher income tended to use $\mathrm{CBHC}$ less than people with lower income. This might indicate that the needs and expectations of people with higher income are met in the Finnish private healthcare system, which they can afford. On the other hand, people with perceived economic hardship used CBHC 
less often than those who did not experience economic hardship. It is possible that economic hardship makes traveling abroad too expensive, even if $\mathrm{CBHC}$ would be preferred. Hence, cross-border utilisation of healthcare seems to be most typical among the middle-income immigrants, who can afford to travel to Russia, but do not necessarily have enough funds for buying private care in Finland. On the other hand, higher education also seems to predict the use of $\mathrm{CBHC}$, which further complicates the socio-economic picture. In terms of social integration, these socio-economic differences may entail a socially stratified impact on integration, as utilising the services of the host society, including healthcare, may facilitate the overall process of integration. These questions of access to health services, economic inequalities and social integration should be examined in further studies. The gendered dimensions of health seeking behaviour and cross-border healthcare also merit more attention in the future.

The strengths and limitations of the study merit attention. The study provided novel, theoretically and practically important information on the social determinants of $\mathrm{CBHC}$, including social integration and the experiences of discrimination. A further advantage of the study was that the survey design covers almost half of the migrants of Russian origin in the country. Moreover, the face-to-face mode of data collection with trained bilingual interviewers yielded a fair participation rate of $55 \%$. In addition, the weighting scheme accounts for non-response. Naturally, as the data are cross-sectional, the coefficients should not be read to flawlessly indicate causal effects. Future studies might be able to utilise longitudinal data to obtain more reliable causal estimates. Furthermore, the case cities do not represent the entire country; as a consequence, the experiences and practices of immigrants living in smaller, less diverse municipalities should be addressed in further studies. Qualitative studies might be able to shed further light on the subjective experiences and meanings related to discrimination in healthcare, social integration and the choice of healthcare provider.

In regards to our findings on parallel use of different healthcare systems, we would like to finish with a concrete policy matter. Nielsen et al. (18) raise a concern regarding patient safety and continuity of care, as well as interference with care from abroad. Also, Lokdam et al. (20) list possible risks of use of cross-border 
healthcare, such as disruption of the continuity of care, lack of follow-up and rehabilitation, risk of poor quality of drugs and the risk of double treatment and/or medication. In addition, lack of trust in the healthcare system in the host-country might lead to postponing treatment to the next trip to one's country of origin, which can be dangerous in serious illness (23). These issues may have negative effects on patients' health, but they may also create unnecessary costs for the healthcare systems. In line with previous studies (19), we found that chronic illness and poor self-rated health were associated with the utilisation of CBHC. Lack of follow-up and the risk of double treatment or medication are grave concerns in regard to chronic illnesses (20), and the treating physicians should be aware of the possible parallel use of cross-border healthcare. The results of our study may inform clinical professionals to pay further attention to medical travel.

\section{Author contributions}

Lyytikäinen and Kemppainen contributed equally as first authors and were responsible of the design of the study, analysis and interpretation of the data, and drafting and revision of the article. Päivikki Koponen and Natalia Skogberg participated in collecting the data. Päivikki Koponen, Hannamaria Kuusio and Natalia Skogberg contributed to the design of the study and provided a critical revision of the article. All authors approved the final version to be published.

\section{Funding statement}

This research was funded by the Academy of Finland and the Kone Foundation (Project: Crossing Borders for Health and Welfare) and the Doctoral Programme in Population Health of the University of Helsinki (Skogberg). The funders were not involved in the study design, data collection, analysis and interpretation of data, writing of the report or in the decision to submit the article for publication.

\section{Ethical approval}

Ethical approval for the study was obtained from the Coordinating Ethical Committee of the Helsinki and Uusimaa Hospital Region.

\section{References}

1. Goddard M, Smith P. Equity of access to health care services: Theory and evidence from the UK. Soc Sci Med 2001; 9: 1149-62

2. Scheppers E, van Dongen E, Dekker J, Geertzen J, Dekker J. Potential barriers to the use of health services among ethnic minorities: a review. Fam Pract 2006; 3: 325-48.

3. Deville W, Greacen T, Bogic M, Dauvrin M, Dias S, Gaddini A, et al. Health care for immigrants in Europe: is there still consensus among country experts about principles of good practice? A Delphi study. BMC Public Health 2011; 1: 1-10. 
4. Wiking E, Saleh-Stattin N, Johansson SE, Sundquist J. Immigrant patients' experiences and reflections pertaining to the consultation: a study on patients from Chile, Iran and Turkey in primary health care in Stockholm, Sweden. Scand J Caring Sci 2009; 2: 290-7.

5. Glinos I, Baeten R, Helble M, Maarse H. A typology of cross-border patient mobility. Health Place 2010; 6: 1145-55.

6. Österle A, Johnson T, Delgado J. A unifying framework of the demand for transnational medical travel. Int J Health Serv 2013; 3: 415-36.

7. Byrd T, Law J. Cross-border utilization of health care services by United States residents living near the Mexican border. Rev Panam Salud Publica 2009; 2: 95-100.

8. Cardenas, V. Cross-border purchase of medications and health care in a sample of residents of El Paso, Texas, and Ciudad Juarez, Mexico. J Natl Med Assoc 2009; 2: 167-73.

9. Su D, Richardson C, Wen M, Pagán J. Cross-Border Utilization of Health Care: Evidence from a Population-Based Study in South Texas. Health Serv Res 2011; 3: 859-76.

10. Horton S, Cole S. Medical returns: seeking health care in Mexico. Soc Sci Med 2011; 11: 1846-52.

11. Su D, Wang D. Acculturation and cross-border utilization of health services. J Imm Min Health 2012; 4: 563-569.

12. De Jesus M, Xiao, C. Cross-border health care utilization among the Hispanic population in the United States: implications for closing the health care access gap. Ethn Health 2013; 3: 297-314.

13. Bertinato L, Busse R, Fahy N, Legido-Quigley H,McKee M, Palm et al. Cross-Border Healthcare in Europe. Policy Brief. Copenhagen: WHO; 2005. 32 p.

14. Wismar M, Palm W, Figueras J, Ernst K, Van Ginneken E. Cross-border health care in the European Union: mapping and analysing practices and policies. Geneve: WHO; 2011. 396 p.

15. Legido-Quigley H, Passarani I, Knai C, Busse R, Palm W, Wismar M, et al. Cross-border healthcare in the European Union: clarifying patients' rights. BMJ 2011: d296.

16. Lunt N, Carrera P. Medical tourism: assessing the evidence on treatment abroad. Maturitas 2010; 1 : 27-32.

17. Martinez A, Chanda R, Smith R. The potential for bi-lateral agreements in medical tourism: a qualitative study of stakeholder perspectives from the UK and India. Global Health 2011; 1: 1-9.

18. Nielsen S, Yazici S, Petersen S, Blaakilde A, Krasnik A. Use of cross-border healthcare services among ethnic Danes, Turkish immigrants and Turkish descendants in Denmark: a combined survey and registry study. BMC Health Serv Res 2012; 390.

19. Şekercan A, Lamkaddem M, Snijder M, Peters R, Essink-Bot M. Healthcare consumption by ethnic minority people in their country of origin. Eur J Pub Health 2015; 3: 384-390. 
20. Lokdam N, Kristiansen M, Handlos L, Norredam M. Use of healthcare services in the region of origin among patients with an immigrant background in Denmark: a qualitative study of the motives. BMC Health Serv Res 2016; 1: 1-10.

21. Migge B, Gilmartin M. Migrants and healthcare: investigating patient mobility among migrants in Ireland. Health Place 2011; 5: 1144-1149.

22. Stan S. Transnational healthcare practices of Romanian migrants in Ireland: Inequalities of access and the privatisation of healthcare services in Europe. Soc Sci Med 2015; Jan: 346-355.

23. Main, I. Medical Travels of Polish Female Migrants in Europe. Sociologicky Casopis 2014; 6: 897.

24. Tiilikainen M. 2008. Somalialaiset maahanmuuttajat ja ylirajainen hoito. Sosiaalilääketieteellinen Aikakauslehti 2008; 1: 74-87. [Somalian immigrants and transnational care]

25. Tiilikainen M, Koehn P. 2011. Transforming the Boundaries of Healthcare: Insights from Somali Migrants. Med Anthropol 2011; 5: 518-44.

26. Lee J, Kearns R, Friesen W. 2010. Seeking affective health care: Korean immigrants' use of homeland medical services. Health Place 2010; 1: 108-15.

27. Penninx R, Spencer D, Van Hear N. Migration and Integration in Europe: the State of Research. Swindon: Economic and Social Research Council; 2008.

28. Sam D, Berry J. Acculturation: when individuals and groups of different cultural backgrounds meet. Pers Psych Sci 2010; 4: 472-81.

29. Strobl R. Social integration and inclusion. In: Ritzes G, editor. Blackwell Encyclopedia of Sociology. Blackwell Publishing. Blackwell Reference Online; 2007. Available from:

http://www.sociologyencyclopedia.com/subscriber/tocnode.html?id=g9781405124331_chunk_g97814051 2433125_ss1-155

30. Danso R. Immigration, Citizenship, and Integration: Social Work Connections. In: Smelser N, Baltes P, editors. International Encyclopedia of the Social \& Behavioral Sciences. 2nd ed. Amsterdam: Elsevier; 2015. p. 7591-7596.

31. Leduc N, Proulx M. Patterns of health services utilization by recent immigrants. J Imm Health 2004; 1: 15-27.

32. Dias $\mathrm{S}$, Milton $\mathrm{S}$, Barros $\mathrm{H}$. Determinants of health care utilization by immigrants in Portugal. $B M C$ Health Serv Res 2008; 1: 1-8.

33. Lebrun L. Effects of length of stay and language proficiency on health care experiences among immigrants in Canada and the United States. Soc Sci Med 2012; 7: 1062-72.

34. Berkman L, Glass T, Brissette I, Seeman T. From social integration to health: Durkheim in the new millennium. Soc Sci Med 2000; 6: 843-57. 
35. Ferguson W, Candib L. Culture, language, and the doctor-patient relationship. Fam Med 2002; 5: 353361.

36. Schouten B, Meeuwesen L.Cultural differences in medical communication: a review of the literature. Pat Edu Couns 2006; 1: 21-34.

37. Norredam M, Krasnik A, Sorensen T, Keiding N, Michaelsen J, Nielsen A. Emergency room utilization in Copenhagen: a comparison of immigrant groups and Danish-born residents. Scand J Pub Health 2004; 1: 53-9.

38. Statistics Finland. Number of persons speaking national languages as their native language went down for the second year in a row; 2016. Available from: http://www.stat.fi/til/vaerak/2015/vaerak_2015_201604-01_tie_001_en.html

39. Finnish Immigration Service. The number of Ingrian Finnish returnees approximately 30,000 - well over 300 applications still expected to arrive; 2016. Available from:

http://www.migri.fi/for_the_media/bulletins/press_releases/press_releases/1/0/the_number_of_ingrian_f innish_returnees_approximately_30_000_well_over_300_applications_still_expected_to_arrive_67538.

40. Vuorenkoski L, Mladovsky P, Mossialos E. Finland: Health system review. Health Systems in Transition 10(4). European Observatory on Health Systems and Policies; 2008.

41. European Commission. Health and long-term care in the European Union. Special Eurobarometer 283/ Wave 67.3; 2007. Available from: http://ec.europa.eu/public_opinion/archives/ebs/ebs_283_en.pdf

42. Kankaanranta T, Vainiomaki J, Autio V, Halila H, Hyppola H, Isokoski I, Kujala S, et al. Factors associated with physicians' choice of working sector: a national longitudinal survey in Finland. Appl Health Econ Health Pol 2006; 2: 125-36.

43. Popovich L, Potapchik E, Shishkin S, Richardson E, Vacroux A, Mathivet B. Russian Federation: Health system review. Health Systems in Transition 13 (7). European Observatory on Health Systems and Policies; 2011.

44. Castaneda A, Rask S, Koponen P, Mölsä M, Koskinen S, editors. Migrant health and wellbeing. A study of persons of Russian, Somali and Kurdish origin in Finland. Helsinki: THL; 2012. Available from: http://urn.fi/URN:ISBN:978-952-245-739-4.

45. Le Roux B, Rouanet H. Multiple Correspondence Analysis. Thousand Oaks: Sage; 2010.

46. Greenacre M. Correspondence Analysis in Practice. 2nd ed. Boca Raton: Chapman \& Hall; 2007.

47. StataPress. Stata Multivariate Statistics Reference Manual. Release 14. College Station: Stata Press; 2015.

48. Ekman S-L, Emami A. Cultural diversity in health care. Scand J Caring Sci 2007; 4: 417-8.

49. Nielsen B, Birkelund R. Minority ethnic patients in the Danish healthcare system-a qualitative study of nurses' experiences when meeting minority ethnic patients. Scand J Caring Sci 2009; 3: 431-7. 
Table 1. Descriptive statistics

\begin{tabular}{|c|c|c|}
\hline & $\%$ & $\mathbf{n}$ \\
\hline \multicolumn{3}{|l|}{ Outcome } \\
\hline Visited physician abroad & 15.4 & 545 \\
\hline \multicolumn{3}{|l|}{ Social integration } \\
\hline Integration (MCA): mean (SD) & $-0.2(1.0)$ & 539 \\
\hline \multicolumn{3}{|l|}{ Basis for residence permit } \\
\hline Ingrian Finnish returnee & 36.4 & 519 \\
\hline Finnish spouse or parent & 27.6 & 519 \\
\hline $\begin{array}{l}\text { Immigrant spouse with a } \\
\text { residence permit }\end{array}$ & 16.2 & 519 \\
\hline Work or study & 17.5 & 519 \\
\hline Other & 2.3 & 519 \\
\hline \multicolumn{3}{|l|}{ Lenght of stay in Finland } \\
\hline less than 5 years & 18.2 & 539 \\
\hline $5-9$ years & 21.0 & 539 \\
\hline $10-14$ years & 25.6 & 539 \\
\hline over 15 years & 35.3 & 539 \\
\hline Finnish citizenship & 44.9 & 539 \\
\hline \multicolumn{3}{|l|}{ Subjective nationality } \\
\hline Russian & 61.3 & 535 \\
\hline Finnish & 13.3 & 535 \\
\hline Some other country & 6.5 & 535 \\
\hline No country & 9.0 & 535 \\
\hline Several countries & 9.9 & 535 \\
\hline \multicolumn{3}{|l|}{ Following Finnish media } \\
\hline Monthly or less frequently & 9.5 & 529 \\
\hline Weekly & 25.0 & 529 \\
\hline Daily & 65.6 & 529 \\
\hline \multicolumn{3}{|l|}{ Command of spoken Finnish } \\
\hline Low & 17.1 & 526 \\
\hline Medium & 39.5 & 526 \\
\hline High & 43.3 & 526 \\
\hline \multicolumn{3}{|l|}{ Amount of Finnish friends } \\
\hline 0 & 61.4 & 498 \\
\hline 1 & 13.1 & 498 \\
\hline 2 & 8.2 & 498 \\
\hline 3 or 4 & 8.6 & 498 \\
\hline 5 or more & 8.6 & 498 \\
\hline
\end{tabular}




\begin{tabular}{|c|c|c|}
\hline $\begin{array}{l}\text { Experienced discrimination in } \\
\text { Finnish healthcare }\end{array}$ & 10.4 & 527 \\
\hline \multicolumn{3}{|l|}{ Parallel use of healthcare systems } \\
\hline $\begin{array}{l}\text { Visited a Finnish physician, past } 12 \\
\text { months }\end{array}$ & 69.0 & 545 \\
\hline \multicolumn{3}{|l|}{$\begin{array}{l}\text { Socio-demographic control } \\
\text { variables }\end{array}$} \\
\hline Age: mean (SD) & $40.1(12.7)$ & 545 \\
\hline Woman & 64.2 & 545 \\
\hline Married or cohabitation & 62.5 & 539 \\
\hline Helsinki region & 60.7 & 545 \\
\hline Tertiary education & 49.5 & 545 \\
\hline \multicolumn{3}{|l|}{ Main activity } \\
\hline Working full-time or part-time & 52.5 & 539 \\
\hline Student & 16.1 & 539 \\
\hline Unemployed & 23.2 & 539 \\
\hline Other & 8.2 & 539 \\
\hline \multicolumn{3}{|l|}{ Monthly household income } \\
\hline More than $2500 €$ & 35.5 & 519 \\
\hline Economic hardship & 47.7 & 537 \\
\hline \multicolumn{3}{|l|}{ Health } \\
\hline Poor self-rated health & 7.1 & 539 \\
\hline Chronic illness & 35.3 & 538 \\
\hline
\end{tabular}


Table 2. Design-based logistic regression results of cross-border health care.

I: Bivariate models

II: Final model

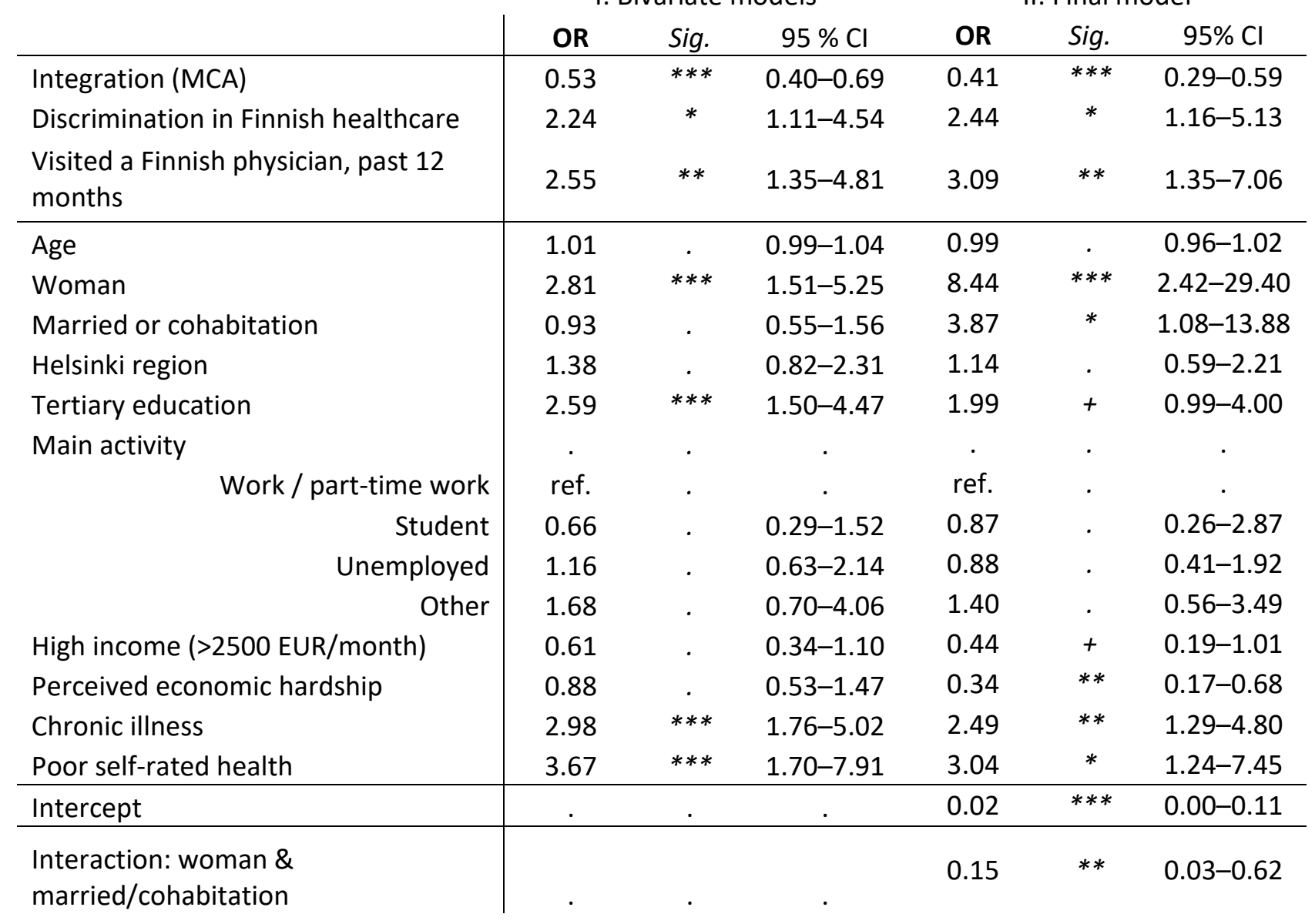

Note: $+p \leq 0.1, * p \leq 0.05,{ }^{* *} p \leq 0.01,{ }^{* * *} p \leq 0.001$ 